\title{
Cone-Beam Computed Tomographic Analysis of Apical Transportation and Centering Ratio of Protaper and XP-Endo Shaper Niti Rotary Systems in Curved Canals: An in Vitro Study
}

\section{Hamed Karkehabadi}

Hamadan University of Medical Sciences School of Dentistry

\section{Zeinab Siahvashi}

Hamadan University of Medical Sciences School of Dentistry

Abbas Shokri ( $\nabla$ dr.a.shokri@gmail.com)

Dental Implant Research Center, Dental School, Hamadan University of Medical Sciences, Hamadan, Iran https://orcid.org/0000-0002-3434-3672

\section{Nasin Haji Hasani}

Islamic Azad University Urmia Branch

\section{Research article}

Keywords: Cone-Beam Computed Tomography, Root canal preparation, Centering ratio, Rotary file

Posted Date: September 30th, 2020

DOI: https://doi.org/10.21203/rs.3.rs-56729/v1

License: (c) (1) This work is licensed under a Creative Commons Attribution 4.0 International License.

Read Full License 


\section{Abstract}

Background: Cleaning and shaping of the root canal system is important in an endodontic treatment. Canal transportation is a common procedural error in preparation of curved canals. This study aimed to compare the canal transportation and centering ratio of two rotary files in curved canals using cone-beam computed tomography (CBCT).

Methods: 44 extracted human mandibular first molars with mature apices and apical curvature of $10^{\circ}$ to $30^{\circ}$ were selected. The samples were randomly divided into two groups $(n=22)$ with similar curvature. The canals were prepared with ProTaper and XP-endo Shaper file systems according to the manufacturers' instructions. CBCT images were captured using Cranex 3D CBCT system before and after root canal preparation, and canal transportation and centering ratio of the files at 3,4 and $5 \mathrm{~mm}$ from the apex were calculated. Data were analyzed and compared between two groups using independent t-test at 0.05 level of significance.

Results: The ProTaper Universal caused greater canal transportation and had lower centering ratio than XP-endo Shaper in both mesiodistal and buccolingual directions at all levels from the apex. The difference between two groups regarding transportation was significant at all levels from the apex in buccolingual direction $(P<0.05)$ except for $3 \mathrm{~mm}$ from the apex $(P>0.05)$. The difference between two groups regarding centering ratio was not significant $(P>0.05)$ in mesiodistal direction at all levels except for $4 \mathrm{~mm}$ from the apex $(P<0.05)$.

Conclusion:The ProTaper Universal causes greater canal transportation in both buccolingual and mesiodistal directions than XP-endo Shaper.

\section{Background}

Root canal cleaning and shaping is important in an endodontic treatment [1]. Root canal preparation with hand files or rotary instruments can cause procedural errors such as canal transportation, ledge formation and zipping [2]. Root canal preparation of curved canals is more difficult and the file has greater tendency to deviate from the main canal path. Canal transportation is a common procedural error that occurs during preparation of curved canals. Canal transportation in the apical third results in debris and microorganisms remaining in the root canal system and subsequently inadequate root canal cleaning and impaired integrity of the root canal system [3]. Evidence shows that rotary nickel titanium ( $\mathrm{NiTi}$ ) files better preserve the shape of main canal path compared to stainless steel files. In the past decades, different rotary systems have been introduced on the market, with a unique design in terms of tip, taper, pitch, and rake and helical angles [2].

ProTaper Universal is an index system and is the gold standard for comparison of new rotary files [4]. Its convex cross-section with a small U-shaped groove in each triangular convex blade has further added to its flexibility and decreased the incidence of apical transportation [2]. Each file pack includes three shaping instruments namely SX, S1 and S2 and three finishing instruments namely F1, F2 and F3. The 
files have colored rings on their shanksused for identification of instrument and application according to the manufacturer's instructions in agreement with the International Organization for Standardization [5].

The novel rotary systems have revolutionized endodontics by using fewer number of files [6]. Recently, XP-endo Shaper system was introduced, which includes a \#30 file with 0.01 taper made of NiTi MaxWire alloy. The MaxWire alloy enables the instrument to undergo transformation when exposed to heat. When exposed to body temperature in the root canal system, takes its predetermined shape. Due to the use of MaxWire alloy, the XP-endo Shaper file is in the martensitic phase at $20^{\circ} \mathrm{C}$ and transforms to austenitic phase when exposed to body temperature in the root canal system [7].

According to the manufacturer, the tip of XP-endo Shaper file has 6 cutting blades which enables the file to start shaping after making a glide path with ISO 15 tip size and gradually increases its efficacy to reach ISO 30 [8]. The XP-endo Shaper can easily adapt to intracanal irregularities and has optimal resistance to cyclic fatigue [9].

At present, there is no standard technique to assess the ability of instruments to remain at the center of canal during root canal preparation and prevent canal transportation [1]. Several methods are used for this purpose. The first method is to assess the canal cross-sections at different levels from the apex. This method is commonly used for direct observation of the shape and position of canal. However, in this method, the main path and position of canal prior to instrumentation cannot be preserved. The second method for this purpose is the Bramante method, in which, first the canals are sectioned prior to instrumentation and then the segments are reassembled and sectioned again to assess changes after instrumentation [10]. The third method is the superimposition of radiographs. In this method, before- and after-instrumentation radiographs are superimposed to determine the changes in the longitudinal shape of the canal two-dimensionally. Although this method is easy and affordable, it has limitations due to the two-dimensional nature of images [11].

CBCT is a valuable non-invasive 3D imaging modality for canal shape assessment after instrumentation, which enables the assessment of changes in volume, surface area, cross-sectional shape and taper of the root canal system [12].

Considering all the above, this study aimed to assess and compare canal transportation and centering ratio after root canal instrumentation with ProTaper and XP-endo Shaper rotary files using CBCT.

\section{Methods}

Mandibular first molars with immature apices extracted for purposes other than this study e.g. periodontal disease and extensive caries were collected. In the surgical ward, before extracting a tooth, the patient completes and signs an informed consent form stating that the extracted tooth will be used in research.The study was approved in the ethics committee of Hamadan University of Medical Sciences (IR.UMSHA.REC.1397.464). Periapical radiographs with photostimulable phosphor plate sensor (Optime, Soredex, Tuusula, Finland) were obtained of the teeth using MinRay intraoral digital radiography system 
(Soredex, Tuusula, Finland). Teeth with calcification, internal or external root resorption, root fracture, severe curvature or curves in two different directions were excluded. Eventually, 44 teeth that met the eligibility criteria were selected.

The curvature angle was measured using the Schneider's method [13]. In order to measure the root curvature, Scanora software (Soredex, Tuusula, Finland) was used. For this purpose, a line was drawn along the longitudinal axis of the tooth. A second line was drawn from the apical foramen to the first point of curvature. The angle formed between the two lines was measured by a caliper, and the curvature angle was determined. Teeth with mesial root curvature between $10^{\circ}$ to $30^{\circ}$ in the mesiodistal plane were enrolled and were divided into two groups with similar degree of curvature (Fig. 1).

The teeth were disinfected with $5.25 \%$ sodium hypochlorite. Access cavity was prepared using a \#4 highspeed round carbide bur (Dentsply Maillefer, Ballaigues, Switzerland). A \#10 K-file (Dentsply Maillefer, Ballaigues, Switzerland) was introduced into the mesiobuccal canal until the file tip was visible at the apex. Next, the working length was measured from the occlusal reference point to $1 \mathrm{~mm}$ shorter of the length of \#10 K-file when its tip was visible at the apex. Next, the crowns were shortened such that the working length was standardized at $19 \mathrm{~mm}$. In order to enhance the radiography and for CBCT images reproducibility, the teeth were mounted in acrylic resin blocks.

All teeth were scanned prior to canal preparation using Cranex 3D CBCT system (Soredex, Tuusula, Finland) with the exposure settings of $90 \mathrm{kVp}, 10 \mathrm{~mA}$ and $12 \mathrm{~s}$ time. Next, a $15 \mathrm{~K}$-file was used for preparation of a glide path. All canals were prepared by the same operator using an endodontic electric motor (X-Smart Plus motor; Dentsply Maillefer, Ballaigues, Switzerland) according to the manufacturer's instructions for the speed and torque of files.

In group $A(n=22)$, the root canals were prepared using ProTaper Universal rotary system (Dentsply Maillefer, Ballaigues, Switzerland). First, SX and then S1 and S2 files were used to flare the orifice and coronal and middle thirds of the mesiobuccal canal in order to create a straight line access. Next, the canals were prepared by F1 and F2 files to the working length.

In group B $(n=22)$, XP-endo Shaper (Dentaire, La Chaux-de-Fonds, Switzerland) was used for root canal preparation. In order to simulate the body temperature, the teeth were kept in water at $37 \pm 1{ }^{\circ} \mathrm{C}$ during root canal preparation [7]. The file tip was introduced into the canal and then the instrument was activated during rotation and long and slow up-and-down movements were performed. When the file reached to working length, up-and-down motions were repeated five times to working length and then the file was removed from the canal while rotating.

After using each file in both systems, recapitulation was performed using a \#15 K-file,and the canals were rinsed with saline. Each file was used for preparation of four canals. Next, the samples were subjected to $\mathrm{CBCT}$ with the same exposure settings as the CBCT prior to instrumentation. 
OnDemand 3D Dental software (Cybermed, Seoul, South Korea) was used to measure the mesiobuccal canal before and after root canal preparation and the degree of root canal transportation and centering ratio were measured at 3,4 and $5 \mathrm{~mm}$ distance from the apex. The shortest distance between canal wall and external root surface in the mesial, distal, buccal and lingual was measured for the mesiobuccal canal. Measurements were made on СВCT scans taken before and after instrumentation as follows [14]:

The degree of canal transportation at each level was determined using the following formula:

$(\mathrm{m} 1-\mathrm{m} 2)-(\mathrm{d} 1-\mathrm{d} 2)$ in the mesiodistal plane and (b1-b2)-(I1-l2) in the buccolingual plane,

Where $\mathrm{d} 1$ is the shortest distance between the distal margin of the rootand the distal margin of uninstrumented canal, d2 is the shortest distance between the distal margin of the root and the distal margin of instrumented canal, $\mathrm{m} 1$ is the shortest distance between the mesial margin of root and the mesial margin of un-instrumented canal, $\mathrm{m} 2$ is the shortest distance between the mesial margin of root and the mesial margin of instrumented canal, 11 is the shortest distance between the lingual margin of root and the lingual margin of un-instrumented canal, 12 is the shortest distance between the lingual margin of the root to the lingual margin of instrumented canal, b1 is the shortest distance between the buccal margin of the root and the buccal margin of un-instrumented canal and b2 is the shortest distance between the buccal margin of the root and the buccal margin of instrumented canal.

The answer of 0 in the aforementioned formula indicates absence of apical transportation.

The canal centering ratio was determined at each level using the following formula:

$(\mathrm{m} 1-\mathrm{m} 2) /(\mathrm{d} 1-\mathrm{d} 2)$ or $(\mathrm{d} 1-\mathrm{d} 2) /(\mathrm{m} 1-\mathrm{m} 2)$ in the mesiodistal plane and (b1 - b2) / (11-I2) or (11-I2) / (b1b2) in the buccolingual plane.

In this formula, smaller values are placed in the numerator and the answer of 1 indicates excellent centering ability (Figs. 2A,B).

The mean and standard deviation values were calculated for both groups. Independent t-test was used to find significant differences between the two groups. $\mathrm{P}<0.05$ was considered as significant.

\section{Results}

Table 1 shows the mean mesiodistal and buccolingual transportation in two systems (Table 1). As shown in Table 1, ProTaper rotary system showed greater canal transportation in mesiodistal and buccolingual directions compared to XP-endo Shaper. The difference in this respect was significant between two systems in the mesiodistal direction at 3,4 and $5 \mathrm{~mm}$ from the apex and in buccolingual direction at 4 and $5 \mathrm{~mm}$ from the apex $(\mathrm{P}<0.05)$. In the buccolingual direction, the difference between two groups was not significant at $3 \mathrm{~mm}$ from the apex $(P>0.05$, Diagram 1$)$. 
Table 1

Mean ( \pm standard deviation) canal transportation in the mesiodistal and buccolingual directions in the two groups

\begin{tabular}{|lllll|}
\hline Direction & \multicolumn{1}{l}{ Distancefrom working length } & $3 \mathrm{~mm}$ & $4 \mathrm{~mm}$ & \multicolumn{2}{l|}{$5 \mathrm{~mm}$} & \\
\cline { 2 - 5 } & Transportation & Mean(SD) & & \\
\hline \multirow{3}{*}{ Mesiodistal } & ProTaper & $0.10(0.10)$ & $0.12(0.08)$ & $0.11(0.09)$ \\
\cline { 2 - 5 } & XP-endo Shaper & $0.03(0.04)$ & $0.03(0.03)$ & $0.04(0.04)$ \\
\cline { 2 - 5 } & P-value & 0.015 & 00 & 0.004 \\
\hline Buccolingual & ProTaper & $0.12(0.15)$ & $0.16(0.11)$ & $0.19(0.16)$ \\
\cline { 2 - 5 } & XP-endo Shaper & $0.08(0.11)$ & $0.08(0.13)$ & $0.08(0.06)$ \\
\cline { 2 - 5 } & p-value & 0.324 & 0.037 & 0.004 \\
\cline { 2 - 5 } & & & & \\
\hline
\end{tabular}

Table 2 shows the mean centering ratio in mesiodistal and buccolingual directions in two systems. As shown in Table 2, the centering ratio of XP-endo Shaper in both directions was higher than that of ProTaper. In the mesiodistal direction, a significant difference was noted in this respect between two groups at $4 \mathrm{~mm}$ from the apex $(P<0.05)$. However, the difference between two groups was not significant at 3,4 and $5 \mathrm{~mm}$ from the apex in the buccolingual direction, and at 3 and $5 \mathrm{~mm}$ from the apex in the mesiodistal direction $(P>0.05$, Diagram 2$)$.

Table 2

Mean ( \pm standard deviation) centeringratio in the mesiodistal and buccolingual directions in the two groups

\begin{tabular}{|lllll|}
\hline Direction & Distancefrom working length & $3 \mathrm{~mm}$ & $4 \mathrm{~mm}$ & \multicolumn{2}{l|}{$5 \mathrm{~mm}$} & \\
\cline { 2 - 5 } & Centering ratio & Mean(SD) & & \\
\hline \multirow{2}{*}{ Mesiodistal } & ProTaper & $0.47(0.30)$ & $0.37(0.28)$ & $0.45(0.28)$ \\
\cline { 2 - 5 } & XP-endo Shaper & $0.53(0.33)$ & $0.63(0.26)$ & $0.61(0.26)$ \\
\cline { 2 - 5 } & P-value & 0.521 & 0.003 & 0.061 \\
\hline Buccolingual & ProTaper & $0.31(0.36)$ & $0.26(0.32)$ & $0.18(0.25)$ \\
\cline { 2 - 5 } & XP-endo Shaper & $0.31(0.38)$ & $0.31(0.37)$ & $0.26(0.30)$ \\
\cline { 2 - 5 } & p-value & 0.977 & 0.609 & 0.384 \\
\cline { 2 - 5 } & & & & \\
\hline
\end{tabular}




\section{Discussion}

One major goal of root canal cleaning is to achieve a conical shape from the apex towards the coronal region and maintain the original canal path [15]. As reported by Weine, when canal transportation occurs, it would be impossible to return to the original shape of the canal especially in curved canals [16]. Assessment of canal transportation and centering ratio is effective to analyze the quality of root canal preparation by different instruments and techniques [17]. According to the American Association of Endodontists, canal transportation is defined as removal of dentin from the root canal walls at the external border of curvature in the apical half of canals due to contact of files since the files tend to straighten up in curved canals [18]. The centering ratio is ability of an instrument to remain at center of canal [14]. In the present study, we chose the mesiobuccal canal of mandibular first molars with $10^{\circ}$ to $30^{\circ}$ curvature because the ledge formation risk, canal transportation and perforation in curved canals, especially the mesiobuccal canal of mandibular molars, is higher [19]. To date, two rotary file groups have been introduced namely the single-file and multi-file rotary systems. This study aimed to compare apical transportation and centering ratio of XP-endo Shaper single-file and ProTaper Universal multi-file systems in extracted teeth using CBCT.

Apical transportation can be quantified using different techniques. However, each technique has its own limitations and there is no gold standard for this purpose [20]. Of the available techniques, CBCT is a noninvasive technique for root canals assessment before and after the instrumentation. It uses cone-shaped X-ray beams and an area detector for acquisition of a cylindrical volume of data. One major advantage of CBCT is to provide cross-sectional and 3D images with high accuracy and resolution. Also, it yields measurable and reproducible results. [3, 21, 22].

In this study, CBCT was used to assess the canal transportation and centering ratio of two rotary systems. To date, no previous study has compared canal transportation of ProTaper and XP-endo Shaper. Aksoy et al. evaluated dentinal microcracks after root canal preparation with ProTaper Universal, XP-endo Shaper and Reciproc Blue using micro-computed tomography and observed that ProTaper Universal resulted in significantly higher number of microcracks [23]. In the present study, ProTaper showed higher canal transportation and lower centering ratio, which was in agreement with the results of Shah, Parsanthi and Rolly who compared ProTaper with LSX and SAF, respectively $[17,24,25]$.

Greater apical transportation caused by ProTaper compared with XP-endo Shaper $(P<0.05)$ may be due to the variable taper along the cutting blade of file, positive rake angle without radial lands and triangular cross-section of ProTaper rotary system [24]. Despite the fact that triangular cross-section increases the flexibility of file, it also increases the cutting efficiency, which can lead to unwanted excessive removal of dentin from the external root canal wall. Moreover, it has been shown that instruments with a constant taper in their apical region have higher centering ability than those with a variable and progressive taper along their cutting blade [26]. Similar results were reported by Sonntag et al, and Schafer and Vlassissince they concluded that ProTaper created the highest amount of canal transportation $(P<0.05)$ when compared with Mtwo, $\mathrm{K} 3$ and RaCe systems $[27,28]$. 
In the present study, XP-endo Shaper showed lower canal transportation and higher centering ratio, which was in agreement with the results of Poly who compared XP-endo Shaper with WOG file [29]. Hassan compared the canal transportation and centering ability of XP-endo Shaper, WaveOne and OneShape rotary systems using $\mathrm{CBCT}$ and showed that XP-endo Shaper better preserved the original canal shape compared with the other two systems [30]. Their results were in agreement with ours.

Optimal results of XP-endo Shaper may be attributed to the adaptive core technology, which helps preserve the original canal anatomy and its curvature [31]. It is believed that XP-endo Shaper applies minimum tension to dentinal walls and thus, can well adapt to root canal irregularities. It seems that XPendo Shaper, in contrast to ProTaper, does not have the usual shape memory of metals and tendency to straighten up. This may explain its higher centering ability and is due to the different fabrication process of its metal alloy, which obviously affects the stress-strain distribution patterns and flexural behaviors. It also confers higher flexibility to the file and decreases its tendency to straighten up in curved canals. Many studies have demonstrated that instruments with higher flexibility have higher centering ability during root canal preparation [32-34]. Apical transportation more than $0.3 \mathrm{~mm}$ can decrease apical seal and compromise the prognosis of treatment [35]. Although the current study showed a significant difference in canal transportation between two systems, canal transportation in both systems was in the range of 0.03 to $0.19 \mathrm{~mm}$, which does not compromise the apical seal. Thus, it may be concluded that both rotary systems have acceptable canal transportation with regard to preservation of the apical seal.

One limitation of this study was evaluation of teeth with moderate curvature. Future studies are required on teeth with severe curvature. Also, ex vivo and in vivo studies are warranted to confirm the current results in a clinical scenario.

\section{Conclusion}

ProTaper Universal rotary system showed higher canal transportation and lower centering ratio than XPendo Shaper in buccolingual and mesiodistal directions at 3, 4 and $5 \mathrm{~mm}$ from the apex. Thus, it may be concluded that XP-endo Shaper better preserves the original canal shape.

\section{Abbreviations}

CBCT: cone-beam computed tomography

\section{Declarations}

\section{Acknowledgement:}

The Vice-Chancellor of Research and Technology of Hamadan University of Medical Sciences provided funding for this study (9708154779). 


\section{Authors'contributions:}

HK were principal investigators, performing root canal therapy; ZS were secondary investigators tooth collection and data measurements during imaging; ASH imaging and writing the original draft and following submission, NHS was involved in the statistical analysis.

All authors read and approved the final manuscript.

\section{Funding:}

The Vice-Chancellor of Research and Technology of Hamadan University of Medical Sciences provided funding for this study (9708154779).

\section{Availability of data and materials:}

The complete documentation of all patients enrolled in this study belong to the authors, and are available only upon reasonable request.

\section{Ethics approval and consent to participate:}

The study was approved in the ethics committee of Hamadan University of Medical Sciences (IR.UMSHA.REC.1397.464).

\section{Consent for publication:}

Not applicable.

\section{Competing interests:}

The authors declare that they have no competing interests in relation to the present study.

\section{References}

1. Nabavizadeh M, Abbaszadegan A, Khojastepour L, Amirhosseini M, Kiani E. A Comparison of Apical Transportation in Severely Curved Canals Induced by Reciproc and BioRaCe Systems. Iranian endodontic journal. 2014;9(2):117-22.

2. Wei Z, Cui Z, Yan P, JiangH. A comparison of the shaping ability of three nickel-titanium rotary instruments: a micro-computed tomography study via a contrast radiopaque technique in vitro. BMC oral health. 2017;17(1):39. 
3. Jain A, Asrani H, Singhal AC, Bhatia TK, Sharma V, Jaiswal P. Comparative evaluation of canal transportation, centering ability, and remaining dentin thickness between WaveOne and ProTaper rotary by using cone beam computed tomography: An in vitro study. Journal of conservative dentistry : JCD. 2016;19(5):440-4.

4. Forghani M, Hezarjaribi M, Teimouri H. Comparison of the shaping characteristics of Neolix and Protaper Universal systems in preparation of severely-curved simulated canals. Journal of clinical and experimental dentistry. 2017;9(4):e556-e9.

5. da Frota MF, Filho IB, Berbert FL, Sponchiado EC, Jr., Marques AA, Garcia Lda F. Cleaning capacity promoted by motor-driven or manual instrumentation using ProTaper Universal system: Histological analysis. Journal of conservative dentistry : JCD. 2013;16(1):79-82.

6. Moazzami F, Khojastepour L, Nabavizadeh M, Seied Habashi M. Cone-Beam Computed Tomography Assessment of Root Canal Transportation by Neoniti and Reciproc Single-File Systems. Iranian endodontic journal. 2016;11(2):96-100.

7. Elnaghy A, Elsaka S. Cyclic fatigue resistance of XP-endo Shaper compared with different nickeltitanium alloy instruments. Clinical oral investigations. 2018;22(3):1433-7.

8. Versiani MA, Carvalho KK, Mazzi-Chaves JF, Sousa-Neto MD. Micro-computed Tomographic Evaluation of the Shaping Ability of XP-endo Shaper, iRaCe, and EdgeFile Systems in Long Ovalshaped Canals. Journal of endodontics. 2018;44(3):489-95.

9. Bayram HM, Bayram E, Ocak M, Uygun AD, Celik HH. Effect of ProTaper Gold, Self-Adjusting File, and XP-endo Shaper Instruments on Dentinal Microcrack Formation: A Micro-computed Tomographic Study. Journal of endodontics. 2017;43(7):1166-9.

10. Javaheri $\mathrm{HH}$, Javaheri $\mathrm{GH}$. A comparison of three $\mathrm{Ni}$-Ti rotary instruments in apical transportation. Journal of Endodontics. 2007;33(3):284-6.

11. Duran-Sindreu F, Garcia M, Olivieri JG, Mercade M, Morello S, Roig M. A comparison of apical transportation between FlexMaster and Twisted Files rotary instruments. Journal of endodontics. 2012;38(7):993-5.

12. Gundappa M, Bansal R, Khoriya S, Mohan R. Root canal centering ability of rotary cutting nickel titanium instruments: A meta-analysis. Journal of conservative dentistry : JCD. 2014;17(6):504-9.

13. Schneider SW. A comparison of canal preparations in straight and curved root canals. Oral surgery, oral medicine, and oral pathology. 1971;32(2):271-5.

14. Gambill JM, Alder M, del Rio CE. Comparison of nickel-titanium and stainless steel hand-file instrumentation using computed tomography. Journal of endodontics. 1996;22(7):369-75.

15. Silva EJ, Muniz BL, Pires F, Belladonna FG, Neves AA, Souza EM, et al. Comparison of canal transportation in simulated curved canals prepared with ProTaper Universal and ProTaper Gold systems. Restorative dentistry \& endodontics. 2016;41(1):1-5.

16. Weine FS. Endodontic therapy: CV Mosby; 2003.

17. Shah DY, Wadekar SI, Dadpe AM, Jadhav GR, Choudhary LJ, Kalra DD. Canal transportation and centering ability of protaper and self-adjusting file system in long oval canals: An ex-vivo cone-beam 
computed tomography analysis. Journal of conservative dentistry : JCD. 2017;20(2):105-9.

18. Eleazer P, Glickman G, McClanahan S. American Association of Endodontists. Clinical Resources. AAE Glossary of Endodontic Terms. 2017.

19. Tasdemir T, Aydemir H, Inan U, Unal O. Canal preparation with Hero 642 rotary Ni-Ti instruments compared with stainless steel hand K-file assessed using computed tomography. International endodontic journal. 2005;38(6):402-8.

20. Iqbal MK, Floratos S, Hsu YK, Karabucak B. An in vitro comparison of Profile GT and GTX nickeltitanium rotary instruments in apical transportation and length control in mandibular molar. Journal of endodontics. 2010;36(2):302-4.

21. Shokri A, Shakibaei Z, Langaroodi AJ, Safaei M. Evaluation of the mandibular canal visibility on cone-beam computed tomography images of the mandible. Journal of Craniofacial Surgery. 2014;25(3):e273-e7.

22. Eskandarloo A, Mirshekari A, Poorolajal J, Mohammadi Z, Shokri A. Comparison of cone-beam computed tomography with intraoral photostimulable phosphor imaging plate for diagnosis of endodontic complications: a simulation study. Oral surgery, oral medicine, oral pathology and oral radiology. 2012;114(6):e54-e61.

23. Aksoy C, Keris EY, Yaman SD, Ocak M, Geneci F, Celik HH. Evaluation ofXP-endo Shaper, Reciproc Blue, and ProTaper Universal NiTi Systems on Dentinal Microcrack Formation Using Micro-Computed Tomography. Journal of endodontics. 2019;45(3):338-42.

24. Prasanthi NN, Rambabu T, Sajjan GS, Varma KM, Satish RK, Padmaja M. A comparative evaluation of the increase in root canal surface area and canal transportation in curved root canals by three rotary systems: A cone-beam computed tomographic study. Journal of conservative dentistry : JCD. 2016;19(5):434-9.

25. Agarwal RS, Agarwal J, Jain P, Chandra A. Comparative Analysis of Canal Centering Ability of Different Single File Systems Using Cone Beam Computed Tomography- An In-Vitro Study. Journal of clinical and diagnostic research : JCDR. 2015;9(5):Zc06-10.

26. Yang GB, Zhou XD, Zheng YL, Zhang H, Shu Y, Wu HK. Shaping ability of progressive versus constant taper instruments in curved root canals of extracted teeth. International endodontic journal. 2007;40(9):707-14.

27. Sonntag D, Ott M, Kook K, Stachniss V. Root canal preparation with the NiTi systems K3, Mtwo and ProTaper. Australian endodontic journal : the journal of the Australian Society of Endodontology Inc. 2007;33(2):73-81.

28. Schafer E, Vlassis M. Comparative investigation of two rotary nickel-titanium instruments: ProTaper versus RaCe. Part 1. Shaping ability in simulated curved canals. International endodontic journal. 2004;37(4):229-38.

29. Poly A, AlMalki F, Marques F, Karabucak B. Canal transportation and centering ratio after preparation in severely curved canals: analysis by micro-computed tomography and double-digital radiography. Clinical oral investigations. 2019. 
30. Hassan R, Roshdy N, Issa N. Comparison of canal transportation and centering ability of Xp Shaper, WaveOne and Oneshape: a cone beam computedtomography study of curved root canals. Acta odontologica latinoamericana : AOL. 2018;31(1):67-74.

31. Azim AA, Piasecki L, da Silva Neto UX, Cruz ATG, Azim KA. XP Shaper, A Novel Adaptive Core Rotary Instrument: Micro-computed Tomographic Analysis of ItsShaping Abilities. Journal of endodontics. 2017;43(9):1532-8.

32. Gergi R, Rjeily JA, Sader J, Naaman A. Comparison of canal transportation and centering ability of twisted files, Pathfile-ProTaper system, and stainless steel hand K-files by using computed tomography. Journal of endodontics. 2010;36(5):904-7.

33. Silva EJ, Tameirao MD, Belladonna FG, Neves AA, Souza EM, De-Deus G. Quantitative Transportation Assessment in Simulated Curved Canals Prepared with an Adaptive Movement System. Journal of endodontics. 2015;41(7):1125-9.

34. Thompson SA, Dummer PM. Shaping ability of Hero 642 rotary nickel-titanium instruments in simulated root canals: Part 2. International endodontic journal. 2000;33(3):255-61.

35. Wu MK, Fan B, Wesselink PR. Leakage along apical root fillings in curved root canals. Part I: effects of apical transportation on seal of root fillings. Journal of endodontics. 2000;26(4):210-6.

\section{Figures}

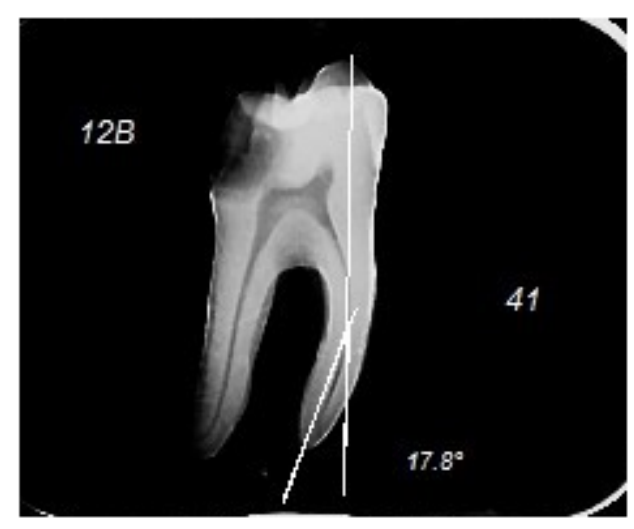

\section{Figure 1}

Measurement of root curvature on a periapical radiograph 
$3 \mathrm{~mm}$
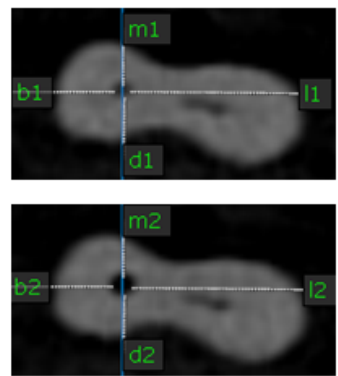

$4 \mathrm{~mm}$
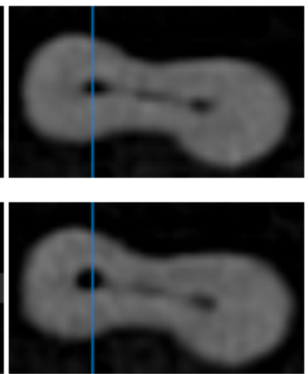

A
$5 \mathrm{~mm}$
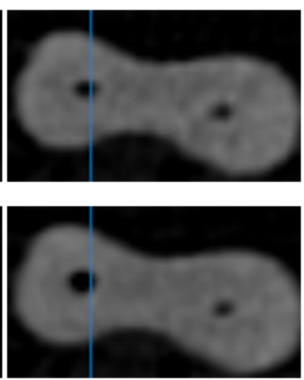

$3 \mathrm{~mm}$
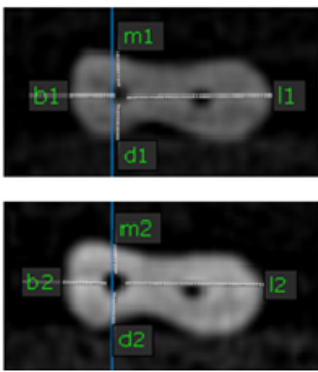

$4 \mathrm{~mm}$
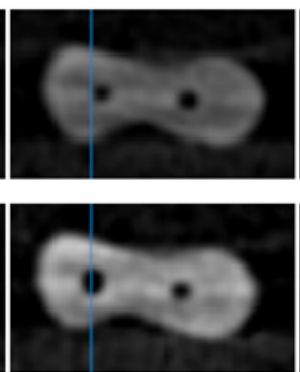

B

Figure 2

A.CBCT scans before and after instrumentation of mesiobuccal canal by XP-endo Shaper at 3,4 and 5 $\mathrm{mm}$ from the apex. B. CBCT scans before and after instrumentation of mesiobuccal canal by ProTaper Universal at 3, 4 and $5 \mathrm{~mm}$ from the apex

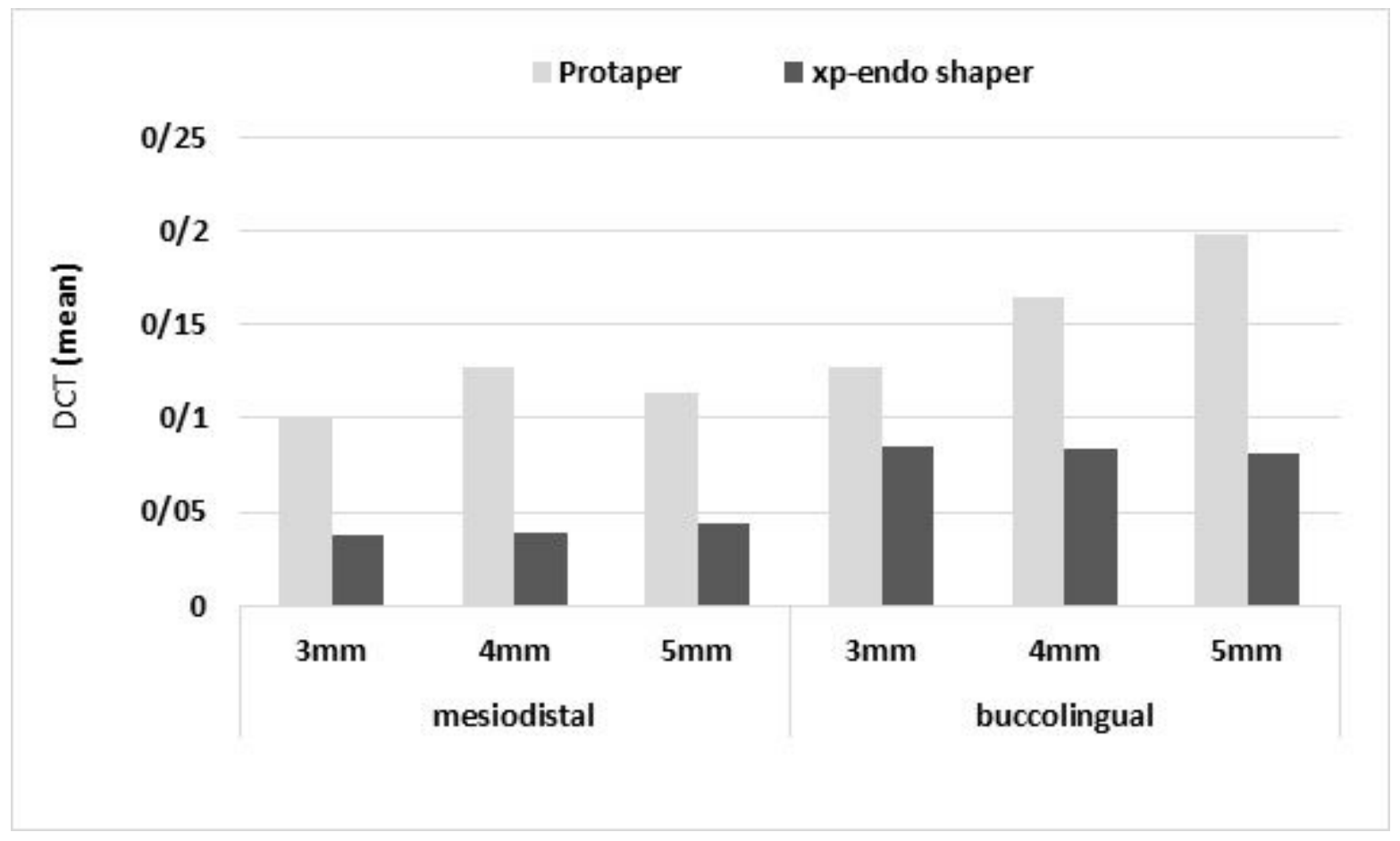

\section{Figure 3}

Diagram 1: Canal transportation at 3, 4 and $5 \mathrm{~mm}$ from the apex in ProTaper and XP-endo Shaper groups. 


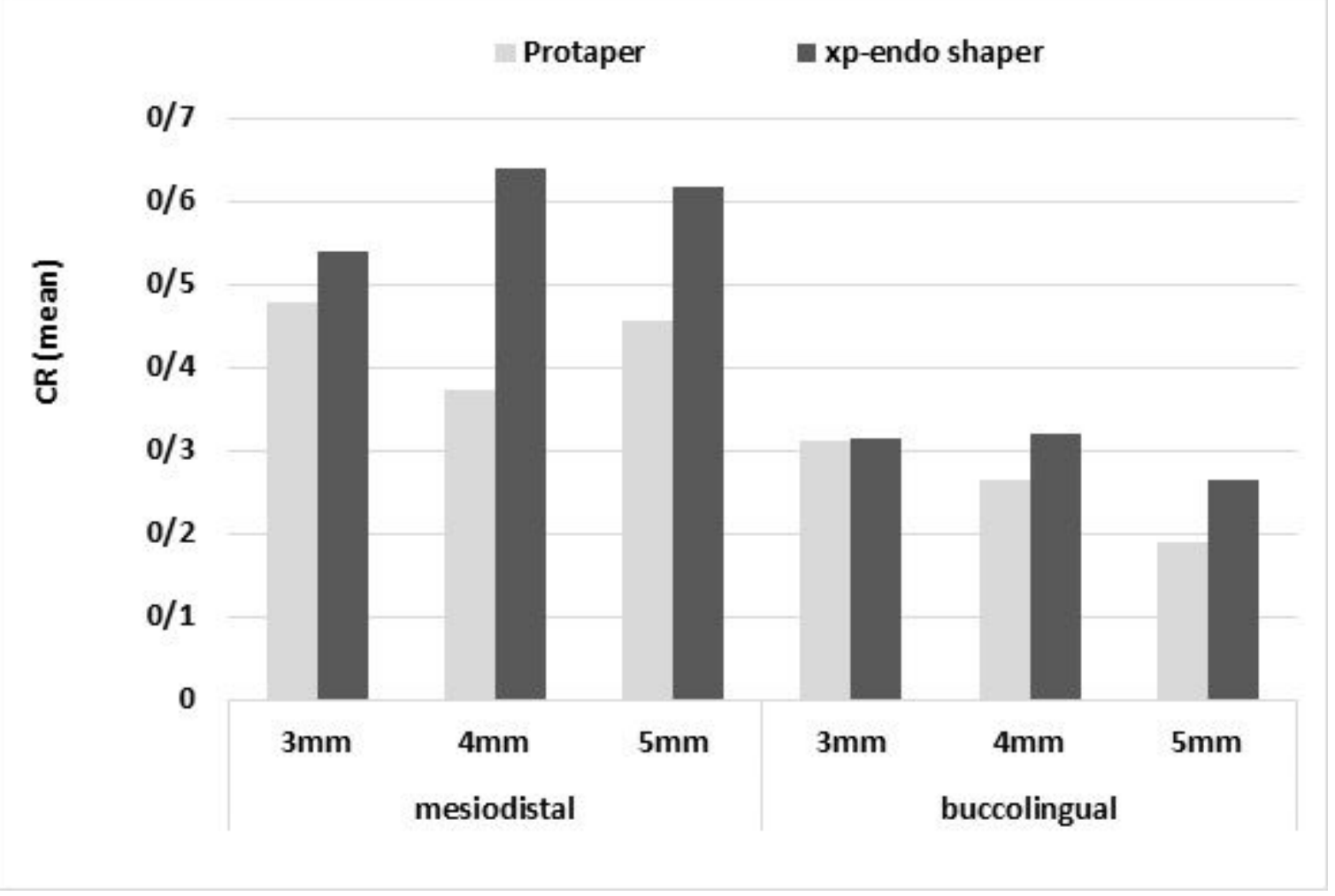

\section{Figure 4}

Diagram 2: Centering ratio at 3, 4 and $5 \mathrm{~mm}$ from the apex in ProTaper and XP-endo Shaper groups 